\title{
Simulation of the Monty Hall Problem
}

\author{
Mazen Alrahili \\ Department of Physics \\ Clark Atlanta University, Atlanta, GA 30314, USA.
}

\begin{abstract}
The Monty Hall problem is a conditional probablity example in which one of three doors has a valuable prize and other two doors conceive worthless "goats." The game features are a rational decision between stay or switch given the constraints of the game. This paper presents simulation results for the original Monty Hall and a variant of two-player Monty Hall problem. The simulation results, based on the analysis of successful frequencies of either option, are useful in clarifying the counter-intuitive nature of the problem.
\end{abstract}

\section{General Terms}

Monty Hall Problem

\section{Keywords}

Monty Hall problem, Simulation, Conditional Probability.

\section{INTRODUCTION}

This paper will provide a simulation model of the Monty Hall problem. Monty Hall was the celebrated host of a TV amusement demonstrate "Let's Make a Deal," one of the best known game shows [10]. As a game show, different configurations of the mainstream program showed up throughout the following 40 years, with the later endeavors accomplishing little prominence contrasted with the projects broadcast in the 1960s and 1970s. In the different versions of the game show that showed up irregularly on TV from 1963 until 2003, diverse solutions to deal with the three doors were presented, with extensions such as incorporating the fourth doors in 1984. Based on the game show, there is well-known math and statistics problem that is referred to as the Monty Hall problem. The game structure and the solution of the Monty Hall problem have been intensively discussed academically. Given the intensive debates regarding the counter-intuitive nature of the solution is the model solution with a simulation that evaluates the frequencies of the possible outcomes (win or lose) under two strategies: switch to the closed door or stay to the initial door. This paper will demonstrate the long-run effects of employing these two strategies. The simulation helps to understand the counterintuitive solution of the Monty Hall problem. In particular, the simulation is useful in establishing the concept of whether the contestant should stay with his or her initial choice or switch to the other door. The solution of the problem that, winning probability double appears counter-intuitive to some contestants.

\section{BACKGROUND}

The Monty Hall Problem has been solved and approved in many different ways, including Bayes' Theorem [11] [12]. The Monty Hall problem has proven in the writing of mathematics and measurements for a long time [1]. Maybe the latest exchange and level headed discussion focused on a daily paper segment by Marilyn vos Savant, which showed up in September 1990. That inquiry was: "Suppose you are on an amusement appear, and you are given the decision of three doors. Behind one door is an auto; behind the others are goats. You pick a door, say 1 and the host, who recognizes what is behind the door, opens the remaining door, say No. 3, which has a goat. He then says to you " Do you need to pick door No. 2?" Is it further bolstering your good fortune to switch your decision? "Craig F. Whitaker, Columbia, MD." Ms. vos Savant reacted that there was the best answer. She expressed that one ought to dependably switch. She went ahead to say that by exchanging, one would have twofold the chances of winning the auto by changing from the first choice. Her answer set off a whirlwind of verbal confrontation and talk. Ms. vos Savant evaluated that she got 10,000 letters and that most couldn't help contradicting her. Probably an essential messages originated from mathematicians and researchers. Noted mathematician Andrew Vazsonyi has composed widely concerning the three doors problem. He even titled his life account Which Door Has the Cadillac: Adventures of a RealLife Mathematician. In an article distributed in Decision Line, Dr. Vazsonyi examines his diversion and disappointment at the powerlessness of the individuals who ought to understand that Ms. vos Savant was unmistakably right in suggesting that exchanging was the best strategy [2]. A particularly intriguing trade happened amongst Vazsonyi and its great companion Paul Erdos. Erdos was “one of the century's most prominent mathematicians, who postured and tackled thorny issues in number hypothesis and different zones and established the field of discrete arithmetic, which is the establishment of software engineering. He was a standout among the most productive mathematicians ever, with more than 1,500 papers to his name." [3] Vazsonyi relates how in 1995, in the wake of referring the goats and Cadillac issue and the answer (dependable switch), Erdos reacted "No. That is impossible." Vazsonyi was persuaded, alongside numerous others, that choice trees would give understanding and help other people to see why the exchanging procedure was the right reply. Hammer developed the selection tree approach in his paper "A Genuine Decision Tree for the Monty Hall Problem." [4] In both the 1999 paper and a subsequent paper distributed in 2003, Vazsonyi talked about the use of reenactment as an answer, and also the requirement for a "nonmathematical" clarification. Vos Savant additionally recommended reproduction as an activity that would edify and convince. There are various intelligent projects which have been produced and are accessible on the web which reenacts the issue. Pretending reproduction has additionally been proposed. Different ways to deal with a classroom way to deal with mimicking the issue have been progressed by Umble and Umble and Taras and Grossman. The key to the use of reproduction of this problem is that the specimen size of the reenactment runs must be adequate. As will be illustrated, here and there countless are required before the result of the Law of Large Numbers can be watched. Additionally, basic is a comprehension of the tenets of the diversion as characterized beforehand. It is conceivable that a misconception of one or a greater amount of the fundamental principles could clarify why such a variety of people neglect to see why exchanging is dependably the better action. Dr. 
Vazsonyi endeavored to give a "non-mathematical" arrangement in 2003. He recognized each likely result for exchanging and tallied the quantities of wins and misfortunes. His methodology is copied in Table 1, with some modifications [5]. As showed in Table 1, of the nine likely results, by exchanging, one will win six times. It is precisely 2 to 1 or a multiplying of the likelihood of winning, as recommended by vos Savant in her daily paper section, and by Vazsonyi and numerous others, mathematicians and nonmathematicians alike.

\section{CLASSICAL MONTY HALL PROBLEM}

The rules of classical Monty Hall Problem are the following:

1. The number of doors in the game is three. At the beginning of the game, a prize will be placed behind each door. Behind one of the doors is a new car. Others two doors are goats.

2. The player will choose one of the doors.

3. The host of the game will open the door to provide the player with an alternative to their choice.

4. After opening one door, the host asks the contestant if he would like to keep his initial selection or switch to the remaining unopened door.

5. The player should make a particular decision to either stay or switch.

6. Should the player stay or change their original choice?

The two following tables will clarify the answer. Table 1 shows that six out of nine results are lost, and three of nine are wins which mean $33.33 \%$ a chance of winning. Table 2 shows that three out of nine results are lost, and six of nine are wins which mean $66.6 \%$ a chance of winning. A player of the Monty Hall problem according to the tables above and the figure 1 below should switch to the other door to be a winner.

\section{MONTY HALL PROBLEM BY SIMULATION MODEL}

The Simulation model is a teaching application that has been used to solve and approve the problem of Monty Hall by EXCEL. The answer clearly indicated that the player should always exchange his or her original choice. Table 3 shows that the statistical average of 1000 times was used by this teaching application.

Table 3: Statistical Average of Running 1000 times

\begin{tabular}{|c|c|c|}
\hline & Switch & No Switch \\
\hline Mean & 64.5 & 34.5 \\
\hline Median & 67 & 32 \\
\hline Mode & 66 & 33 \\
\hline Minimum & 54 & 18.5 \\
\hline Maximum & 80 & 46 \\
\hline
\end{tabular}

\section{CONCLUSION}

The spreadsheet recreation model displayed in this paper is proposed to give knowledge to the great Monty Hall problem and give an option way to deal with use in instructing the related likelihood standards. Various methodologies have been used to clarify why exchanging a door will increase the likelihood of winning in the wake of seeing a door, not the one with the auto and not the one at first chosen by the candidate. For a few, the likelihood or choice tree is the favored instrument for investigation. Others have used pretending in a classroom domain. The exchange and public argument created by the illogical right arrangement proceeds right up 'til the present time. It is significant that no less than one expert mathematician who at first assaulted Ms. vos Savant had the fearlessness to concede his mistake. Robert Sachs of George Mason University had first tested vos Savant and said that she was off base by composing her, "I'm exceptionally worried about the overall population's absence of scientific abilities. It will be ideal if you help by admitting your error." After understanding that vos Savant was, in fact, right, and he wasn't right, he spoke with her. "I thought of her another letter advising her that in the wake of expelling my foot from my mouth, I'm presently trying to back-peddle. I promised as an atonement to answer every one of the general population who composed to rebuke me. It's been an extraordinary expert embarrassment. Perhaps a misconception of the suppositions and principles, as already talked about, is an incomplete clarification of the failure of people to get a handle on the issue. Maybe it is that the right answer is illogical. As vos Savant expressed, "When reality conflicts so viciously with instinct individuals are shaken" Such is regularly the case with business measurements understudies, particularly the individuals who depend on original arrangements and plans for problem including probabilities (e.g. are these occasions free?). Deciding the likelihood of copy birthdays in a classroom of understudies, a frequently utilized classroom demonstration has a tendency to be irrational [6]. It is the trust of the writers that the spreadsheet recreation model methodology laid out in this paper will give an option way to deal with both educating and comprehension the significant likelihood issue known as the Monty Hall problem.

\section{ACKNOWLEDEMENTs}

The author would like to thank X.Q. Wang for his useful comments and suggestions during the preparation of the manuscript. Support from Saudi Arabian Cultural Mission funds research is greatly appreciated.

Table 1: Monty Hall Problem (not- Switching) stay Strategy

\begin{tabular}{|l|l|l|l|l|l|}
\hline $\begin{array}{l}\text { Case } \\
\text { Number }\end{array}$ & $\begin{array}{l}\text { Car } \\
\text { Behind }\end{array}$ & $\begin{array}{l}\text { You } \\
\text { Guess }\end{array}$ & $\begin{array}{l}\text { Monty } \\
\text { Opens }\end{array}$ & Stay & Results \\
\hline 1 & 1 & 1 & 2 or 3 & 1 & Win \\
\hline 2 & 1 & 2 & 3 & 2 & Lose \\
\hline 3 & 1 & 3 & 2 & 3 & Lose \\
\hline 4 & 2 & 1 & 3 & 1 & Lose \\
\hline 5 & 2 & 2 & 1 or 3 & 2 & Win \\
\hline 6 & 2 & 3 & 1 & 3 & Lose \\
\hline 7 & 3 & 1 & 2 & 1 & Lose \\
\hline 8 & 3 & 2 & 1 & 2 & Lose \\
\hline 9 & 3 & 3 & 1 or 2 & 3 & Win \\
\hline
\end{tabular}


Table 2: Monty Hall Problem switching Strategy

\begin{tabular}{|l|l|l|l|l|l|}
\hline $\begin{array}{l}\text { Case } \\
\text { Number }\end{array}$ & $\begin{array}{l}\text { Car } \\
\text { Behind }\end{array}$ & $\begin{array}{l}\text { You } \\
\text { Guess }\end{array}$ & $\begin{array}{l}\text { Monty } \\
\text { Opens }\end{array}$ & $\begin{array}{l}\text { Switch } \\
\text { to }\end{array}$ & Results \\
\hline 1 & 1 & 1 & 2 or 3 & 3 or 2 & Lose \\
\hline 2 & 1 & 2 & 3 & 1 & Win \\
\hline 3 & 1 & 3 & 2 & 1 & Win \\
\hline 4 & 2 & 1 & 3 & 2 & Win \\
\hline 5 & 2 & 2 & 1 or 3 & 3 or 1 & Lose \\
\hline 6 & 2 & 3 & 1 & 2 & Win \\
\hline 7 & 3 & 1 & 2 & 3 & Win \\
\hline
\end{tabular}

\begin{tabular}{|l|l|l|l|l|l|}
\hline 8 & 3 & 2 & 1 & 3 & Win \\
\hline 9 & 3 & 3 & 1 or 2 & 2 or 1 & Lose \\
\hline
\end{tabular}

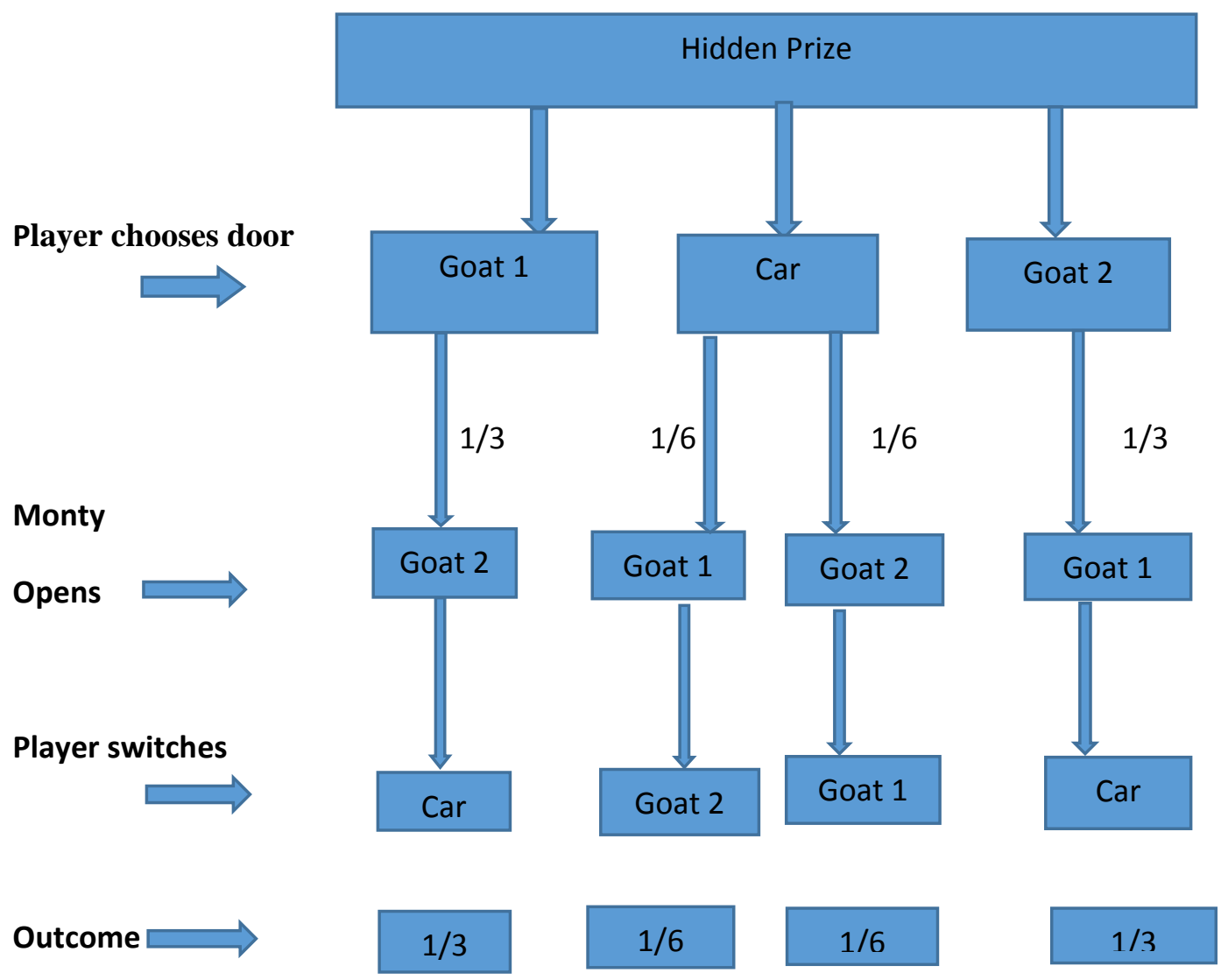

Final Results of Switching

$$
\begin{aligned}
& (1 / 3)+(1 / 3)=2 / 3 \text { of winning a car } \\
& (1 / 6)+(1 / 6)=1 / 3 \text { of losing a car }
\end{aligned}
$$

Figure 1: Classical Model of the Monty Hall problem. 


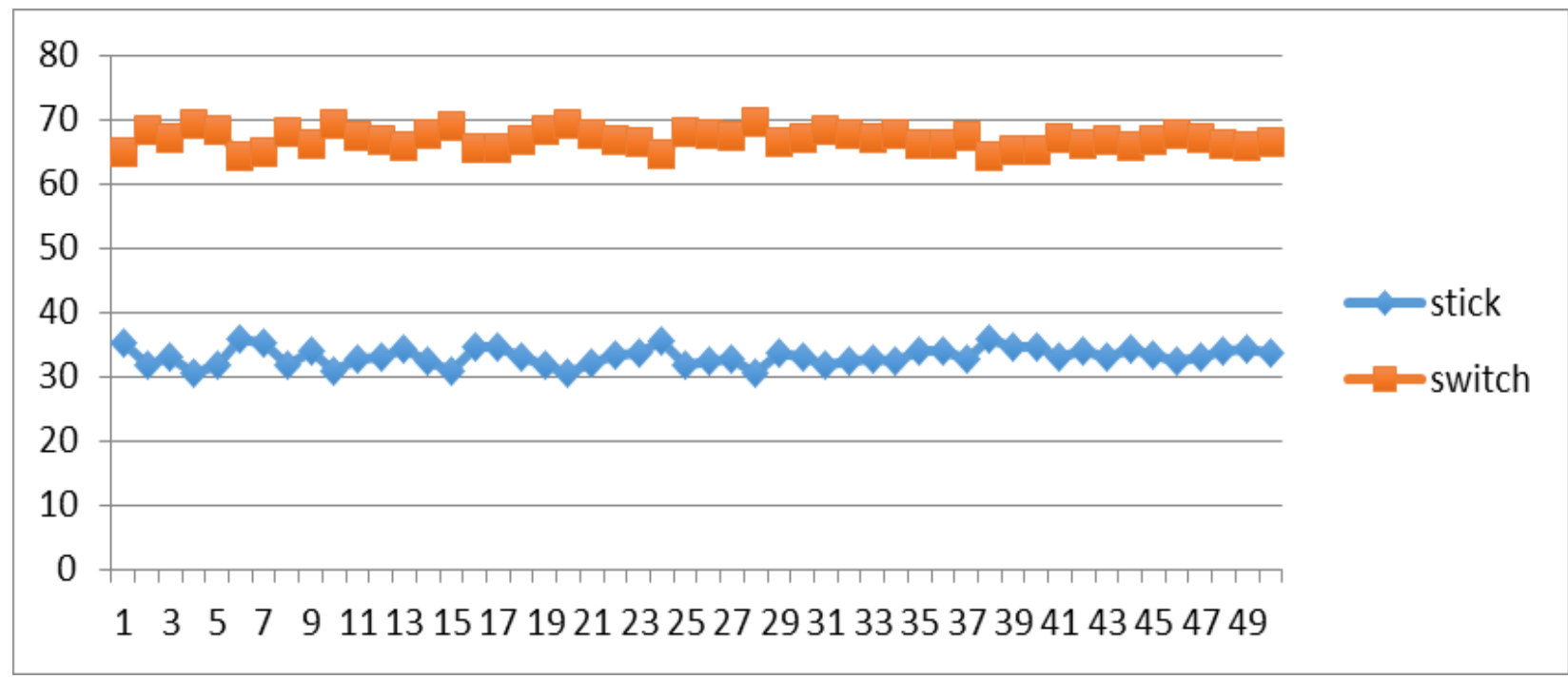

Figure 2: The percentage between sticking and switching.

\section{REFERENCES}

[1] Bowman, M., Debray, S. K., and Peterson, L. L. 1993. Reasoning about naming systems.

[2] Ding, W., and Marchionini, G. 1997 A Study on Video Browsing Strategies. Technical Report. The university of Maryland at College Park.

[3] Fröhlich, B., and Plate, J. 2000. The cubic mouse: a new device for three-dimensional input. In Proceedings of the SIGCHI Conference on Human Factors in Computing Systems

[4] Tavel, P. 2007 Modeling, and Simulation Design. AK Peters Ltd.

[5] Sannella, M. J. 1994 Constraint Satisfaction and Debugging for Interactive User Interfaces. Doctoral Thesis. UMI Order Number: UMI Order No. GAX9509398., The university of Washington.

[6] Forman, G. 2003. An extensive empirical study of feature selection metrics for text classification. J. Mach. Learn. Res. 3 (Mar. 2003), 1289-1305.
[7] Brown, L. D., Hua, H., and Gao, C. 2003. A widget framework for augmented interaction in SCAPE.

[8] Y.T. Yu, M.F. Lau, "A comparison of MC/DC, MUMCUT and several other coverage criteria for logical decisions," Journal of Systems and Software, 2005, in press.

[9] Spector, A. Z. 1989. Achieving application requirements. In Distributed Systems, S. Mullender.

[10] Rosenhouse, J. (2009) The Monty Hall Problem. Oxford University Press, New York.

[11] Wang, J. L., Tran, T. and Abebe, F. (2016) Maximum Entropy and Bayesian Inference for the Monty Hall Problem.Journal of Applied Mathematics and Physics, 4 1222-1230. doi: 10.4236/jamp.2016.47127.

[12] Wang, J. L., Tran, T., Abebe, F. and Wang, X.-Q. (2016) Rational Decisions in Bayesian Games, Proceedings of Dynamic Systems and Applications, 7, 339-341. 